\title{
Field trial of graded care profile (GCP) scale: a new measure of care
}

\author{
O P Srivastava, L Polnay
}

\begin{abstract}
Aim-The graded care profile (GCP) scale was developed as a practical tool in response to the Children Act 1989 to provide a measure of care in four areas: physical, safety, love, and esteem, on a bipolar continuum. This field trial was to assess its user friendliness and inter-rater agreement.

Methods-43 nursery children and 11 registered for neglect were each scored on this scale independently by two different raters (health visitor and nursery teacher or social worker). Their inter-rater agreement was assessed by weighted $\kappa$ and user friendliness by time taken for and completeness of scoring.

Results-An almost perfect level of agreement was achieved in physical care $(\kappa=$ 0.899; confidence interval $(\mathrm{CI})=0.850$ to $0.948)$, safety $(\kappa=0.894 ; \mathrm{CI}=0.854$ to $0.933)$, esteem ( $\kappa=0.877 ; \mathrm{CI}=0.808$ to $0.946)$, and a substantial level in love $(\kappa=$ $0.785 ; \mathrm{CI}=0.720$ to 0.849$)$. Mean time taken for scoring was $\mathbf{2 0}$ minutes (range 10 to 30); of 54 paired scales, area of safety was not scored only in three by one of the raters.

Conclusions-This scale appeared user friendly and provided grading of care with high inter-rater agreement. Its use in practice could provide an opportunity for useful comparison with other means of assessment of care, studying outcomes of different care profiles, targeting intervention, and monitoring change.

(Arch Dis Child 1997;76:337-340)
\end{abstract}

Keywords: parenting; child protection; neglect

The Children Act 1989 has introduced two concepts in child protection-parental responsibility, and harm attributable to care. ${ }^{1}$ This raises issues of the exercise of parental responsibility and the need for objectivity in assessing harm attributable to care. This scale was developed by exploring issues around the care process in an attempt to find a more objective way of assessment.

Care has been divided into four areas based on the needs of the child, adopted from Maslow's hierarchy of human needs. ${ }^{2}$ These areas are: physical care, safety, love, and esteem. The graded care profile (GCP) scale provides separate grading for each of these areas.

In this scale there are five grades of care, distributed on a bipolar continuum based on Bel- sky's model. ${ }^{3}$ Grade 1 is at the positive and grade 5 at the negative end of the continuum. Scoring is done on actual care delivered and the carers' effort, intention, and commitment in relation to their child's needs. For ease of use, constructs are prepared for each of the grades against items of care and printed as a coding manual.

This is a new scale designed to be used by all individuals working with or caring for children, including parents. The purpose of this field trial was to assess its user friendliness and inter-rater agreement.

\section{Methods}

SUBJECTS

A field trial was conducted from April 1994 to February 1995. The procedure was fitted in with routine working practices to maintain a near normal setting. All children were visited at home by nursery staff before they started at their nursery. We preferred this prenursery stage, as care was entirely home based. We selected four of the nurseries which volunteered to give a fair spread of socioeconomic status (nursery group). Children of similar age who were on the register for neglect were also included, to test the whole range of grades rather than to act as controls (neglect group). From a complete list of subjects for both groups, those whose parents/guardians had consented were selected for their home care rating on the GCP scale.

\section{RATERS}

For nursery group subjects the raters were their prospective nursery teacher and health visitor. For the neglect group, raters were their social worker and health visitor. A group training session was arranged for prospective raters. Those who could not attend were trained individually.

Once subjects in the nursery group had been rated by their prospective nursery teacher, the scale was returned to the main health centre. This triggered a visit and an independent rating by their health visitor within the next two weeks. In the neglect group, the social worker of the subject was first asked to rate and then the health visitor. All raters were asked to indicate the time they took to score, and to score for as many areas as they could reliably manage. All completed scales were collated by a clerk at the main health centre.

THE SCALE

There are three parts to the scale (fig 1) - the record sheet, the coding manual, and instructions. The record sheet is a single sheet of paper 


\begin{tabular}{|c|c|c|c|c|c|c|c|c|}
\hline AREAS & Subareas & \multicolumn{5}{|c|}{ Scores } & Area & Comments \\
\hline \multirow{5}{*}{ 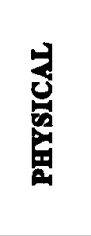 } & NUTRITION & 1 & 2 & 3 & 4 & 5 & \multirow{5}{*}{3} & \\
\hline & CLOTHHING & 1 & 2 & 3 & 4 & 5 & & \\
\hline & HYGIENE & 1 & 2 & 3 & 4 & 5 & & \\
\hline & HOUSING & 1 & 2 & 3 & 4 & 5 & & \\
\hline & HEALTH & 1 & 2 & 3 & 4 & 5 & & \\
\hline \multirow{2}{*}{ 촐 } & IN CARER'S PRESENCE & 1 & 2 & 3 & 4 & 5 & \multirow{2}{*}{3} & \\
\hline & IN CARER'S ABSENCE & 1 & 2 & 3 & 4 & 5 & & \\
\hline \multirow{2}{*}{ 是 } & CARER & 1 & 2 & 3 & 4 & 5 & \multirow{2}{*}{2} & \\
\hline & MUTUAL ENGAGEMENT & 1 & 2 & 3 & 4 & 5 & & \\
\hline \multirow{4}{*}{ 䆞 } & STIMULATION & 1 & 2 & 3 & 4 & 5 & \multirow{4}{*}{2} & \\
\hline & APPROVAL & 1 & 2 & 3 & 4 & 5 & & \\
\hline & DISAPPROVAL & 1 & 2 & 3 & 4 & 5 & & \\
\hline & ACCEPTANCE & 1 & 2 & 3 & 4 & 5 & & \\
\hline
\end{tabular}

Grades: 1 = best, 2 = adequate, 3 = inadequate, $4=$ poor, $5=$ worst.

(Grades in a subarea are obtained by matching the information in a case relating to that subarea with corresponding construct in the coding manual).

Example of subarea of 'disapproval' (area of 'esteem') from the manual:-

Grade 1 = Consistent verbal 'disapproval' for any uacceptable behaviour.

Grade 2 = Consistent terse verbal disapproval or mild sanctions.

Grade 3 = Inconsistent, shouts, or moderate sanctions.

Grade 4 = Harsh inconsistent or moderate sanctions for inconvenience.

Grade 5 = Terrorise, ridicule, or severe sanctions.

(Score for an area is worked from subarea scores as described in instructions).

Figure 1 Record sheet for the graded care profile scale.

which displays areas and their component subareas of care, with five grades alongside. The grades for subareas are obtained by matching the information on carer-child observation with the closest graded category in the coding manual. From these, a final score is derived for each of the main areas, applying the rules described in the instructions.

ANALYSIS

The ability of the scale to yield consistent results was tested through comparison of the scores obtained by each pair of raters. Statistical analysis was carried out by weighted $\kappa$, which gives a measure of inter-rater agreement taking minor variations into account. ${ }^{4}$

User friendliness was assessed by the time taken and completeness of scoring the different areas. A target of half an hour was set. Raters

Table 1 Status of subjects and completeness of scores

\begin{tabular}{lllllll}
\hline Subjects & $\begin{array}{l}\text { Initial } \\
\text { No }\end{array}$ & $\begin{array}{l}\text { No } \\
\text { consented }\end{array}$ & $\begin{array}{l}\text { Scales not } \\
\text { paired }\end{array}$ & $\begin{array}{l}\text { One area not } \\
\text { scored }\end{array}$ & $\begin{array}{l}\text { No } \\
\text { moved out }\end{array}$ & $\begin{array}{l}\text { Final } \\
\text { No }\end{array}$ \\
\hline Nursery & 55 & 55 & 12 & 3 (Safety) & 0 & 43 (Saf 40) \\
Neglect & 15 & 13 & 0 & 0 & 2 & 11 \\
Total & 70 & 68 & 12 & 3 & 2 & 54 (Saf 51) \\
\hline
\end{tabular}

Saf $=$ area of 'Safety'. were also asked to record any comments they might have on the scale.

\section{Results}

Parents of all 55 children in the nursery group consented, but for 12 of these one of the raters could not find time to pair the rating. In three of the 43 paired scales nursery teachers did not score for safety, leaving only 41 paired scores for this area. Of 15 children in the neglect group, the parents of two did not consent and a further two had moved out of the area, leaving 11 paired scales which were scored in all areas. Thus there were 54 paired scores for all areas, but 51 for safety (table 1 ).

Ten health visitors, eight nursery teachers, and 10 social workers took part in the rating.

The mean time taken to score was 20 minutes (range 10 to 30 ). All 108 scales (54 pairs) were scored in all areas of care, except safety in three $(2.7 \%)$. Thus $97.3 \%$ of scales completed scoring in all areas. The raters who scored more subjects took considerably less time in subsequent subjects as they became used to scoring.

The $\kappa$ value conventionally denotes one of the six levels of agreement-poor, slight, fair, 
Table 2 Showing weighted $\kappa$ in each area of care

\begin{tabular}{lll}
\hline Areas & $\kappa$ & $95 \%$ confidence interval \\
\hline Physical & 0.899 & 0.850 to 0.948 \\
Safety & 0.894 & 0.854 to 0.933 \\
Love & 0.785 & 0.720 to 0.849 \\
Esteem & 0.877 & 0.808 to 0.946 \\
\hline
\end{tabular}

moderate, substantial, and almost perfect. ${ }^{5}$ An almost perfect level of agreement ( $\kappa$ 0.81-1) was achieved in the areas of physical care, safety, and esteem; and a substantial level $(\kappa$ $0.61-0.8)$ in the area of love and 'belongingness' (table 2).

Comparing the two groups, complete agreement was $24 \%$ better in the neglect group (health visitors and social workers) in the area of 'love' than in the nursery group (health visitors and nursery teachers). In other areas no differences emerged (table 3 ).

\section{Discussion}

The graded care profile scale is based on the concept of continuum and incorporates isolated known principles and research findings into a new framework. This new design was tested in this field trial. All the 28 raters managed to use the scale after an hour of training. Those who scored several subjects found it considerably easier and quicker on successive occasions. These results show that the design was user friendly in practice. It is possible that the health visitors had additional information, or were professionally more adept in observing or interviewing for safety. Further training emphasising this point could overcome this problem.

The level of agreement was high (table 2). Although good enough agreement can be achieved in extreme cases of neglect of care without such a scale (Stones B, in workshop on neglect, Barnsley NSPCC, 1995; personal communication), the level was greater here in both extreme and intermediate grades. Complete agreement was achieved in relatively more cases in the neglect group than in the nursery group of subjects in the area of 'love' but not in other areas. However, that difference disappeared if one grade variation was included (table 3). This suggests the scale was able to provide a measure of care with low inter-rater variation. This is acceptable for a descriptive scale of this nature if it were to be used in practice. As yet it cannot be used to predict an outcome. However, it does offer an objective measurement to define different grades of care. It can be used in parallel with established practices to provide evidence regarding child care

Table 3 Comparison of complete agreement and agreement within one grade difference in percentages in the two groups of subjects

\begin{tabular}{|c|c|c|c|c|}
\hline \multirow[b]{2}{*}{ Areas } & \multicolumn{2}{|c|}{$\%$ Agreement, nursery grade } & \multicolumn{2}{|c|}{$\%$ Agreement, neglect grade } \\
\hline & Complete & $\begin{array}{l}\text { One grade } \\
\text { difference }\end{array}$ & Complete & $\begin{array}{l}\text { One grade } \\
\text { difference }\end{array}$ \\
\hline Physical & 72 & $98^{\star}$ & 73 & 100 \\
\hline Safety & 63.50 & 100 & 64 & 100 \\
\hline Love & 49 & 100 & 73 & 100 \\
\hline Esteem & 77 & $98^{\star}$ & 64 & 100 \\
\hline
\end{tabular}

*A single case where the pair of raters disagreed by two grades in those areas. outcome in terms of growth and development, and child protection. A simultaneous display of grades of care in all areas would be useful in identifying targets and deciding the nature of intervention, by picking areas with deficient care without losing sight of other areas, or by setting objectives for a better grade. It can then be used for monitoring progress by tracking the targeted areas.

Currently there are four ways of assessing care. Commonly practitioners use their own internal references to assess care, based on their beliefs, training, and experience. A second way is to use scales developed in the context of neglect. ${ }^{6-8}$ These are based on characteristics of neglectful families (registered as neglect). Presence of sufficient of these characteristics in a given case indicates neglect. These reference numbers are derived from a sample. Thus at best they define neglectful or non-neglectful care. If care is good in a certain area it cannot be scored. A third way is to use a scale like the HOME inventory, which focuses on cognitive development. ${ }^{9}$ However, this is also based on a reference score derived from a sample which gives a cut off point rather than being a direct categorical scale based on a continuum. A fourth approach is to estimate care by clinical observation of behavioural characteristics correlated by various investigators with poor attachment or care. Examples include the Ainsworth strange situation, ${ }^{10}$ the feeding behaviour rating scale, ${ }^{11}$ and the approachwithdrawal scale. ${ }^{12}$ They all have exceptions as behaviour is multiply determined and they also need a high level of expertise. ${ }^{13}$ In addition they are more age dependent and do not give a measure of care in all areas. Their yield could be enhanced if used concurrently with a direct measure of care like the GCP.

The grades of GCP scale are a measure of strength of 'caring instinct' reflected through the carer's effort, intention, and contribution to the actual care. The strength of the caring instinct is manifest by its ability to buffer the ill effects of adverse factors in socioeconomic context, child's attributes, and carer's attributes upon the care process. ${ }^{3}$ This protective or sparing effect should be shown up by this scale. These factors are not accounted for separately from their observed effect on actual care delivered. This enables the GCP to identify carers who continue to provide satisfactory care in spite of the presence of adverse factors. Parenting behaviour, such as too little or too much control of the child, which though possibly detrimental is not due to neglect, may not show up on this scale. However, it may if too little control is due to overprotectiveness or neglect; in the former, scores should be better in areas of love and safety as well as in the area of esteem (mild or little disapproval). Such carers may not have insight and may seek help with their child's behavioural problems. We would argue that, being caring enough, they may be receptive of expert evaluation and advice. They may not raise child protection issues.

Care can be uniformly good in all areas, or variable, being good in one but not in other 
areas. The net effect on a child of an uneven care profile will depend on the severity of deficiency in a particular area, the buffering effects of good care in other areas, and the child's innate characteristics. Profiling (good or bad care in all areas on the same scale) provides an opportunity to analyse child outcome in this way. Profiling also helps identify in which areas care is deficient. Improvement over time can be reflected through changes in score towards the better grades.

CONCLUSION

The GCP scale for measurement of care is a new design. In this field trial it appeared workable in routine practice. It was found to be user friendly and gave a measure of care with high inter-rater agreement, showing strengths and weaknesses in four areas - physical, safety, love, and esteem. Its use in conjunction with other conventional practices in a variety of situations where care is a matter of interest provides a new reference point. With time, it may provide a better understanding of the effect of care on children, especially where care varies in different areas (uneven profile). In addition to care assessment, it can also be of use in targeting intervention and monitoring changes. It can be used by professionals working with children in different agencies such as education, social services, and health.

1 Home Office. Working together under the Children Act 1989. London: HMSO, 1991.

2 Maslow AH. Motivation and personality. New York: Harper and Row, 1954.

3 Belsky J. The determinants of parenting: a process model. Child Dev 1984;55:83-96.

4 Altman DG. Practical statistics for medical research. London: Chapman and Hall, 1991.

5 Landis JR, Koch GG. The measure of observer agreement for categorical data. Biometrics 1977;33:159-74.

6 Polansky NA, Gaudin JM, Kilpatrick AC. The maternal characteristics scale: a cross validation. Child Welfare 1992; 71:271-80.

7 Gaudin JM, Polansky NA, Kilpatrick AC. The child well-being scale: a field trial. Child Welfare 1992;71:319-28. 8 Minty B, Pattinson G. The nature of child neglect. $\mathrm{Br} \mathrm{f}$ Social Work 1994;24:733-47.

9 Caldwell BM, Bradley RH. Home observation for measure of the environment. Little Rock, Arkansas: University of Arkansas, 1984 (unpublished).

10 Ainsworth MDS, Behar MC, Waters E, Walls S. Patterns of attachment: a psychological study of strange situation. Hillsdale NJ: Erlbaum, 1978.

11 Dietrich KN, Starr RH, Weisfeld GE. Infant maltreatment: caretaker-infant interaction and developmental consequences at different levels of parenting failure. Pediatrics 1983;72:532-40

12 Rosenn W, Loeb LS, Jura MB. Differentiation of the non-organic failure to thrive syndrome in infancy. Pediatrics 1980;66:698-704.

13 Mussen PH, Kagan J, Conger JJ, Huston AC. Child development and personality. 7th Ed. New York: Harper Collins, 1990. 